\title{
EDITORIAL
}

\section{Change and conflict}

Jaime ALMANSA SÁNCHEZ, Editor Elena PAPAGIANNOPOULOU, Editor

At the time of writing this editorial, as the new year is already underway, we are taking an introspective glance balanced with rational self-criticism. To begin with, even though the debate about current publishing models is ongoing, there is no internal conflict surrounding our work for the journal. It is our firm belief that the quality and accessibility of academic publications rather than impact factor and quantitative metrics should be a priority. We work with this principle in mind, aiming at the same time at being as inclusive and representative as possible. The downside of our model, apart from time constraints, is that we rely entirely on the donations we receive. Thus, there is no funding stability, the latter being one of the key sustainability factors. On the bright side, we are still here and our model's virtue, apart from being freely and fully available for readers around the globe provided that they have internet access, is that publishing with us does not involve open access fees for authors.

In this context we have recently taken an important decision with the aim of improving the journal's quality and reach: we have now migrated to Open Journal Systems, hoping it can offer a better platform for the management and diffusion of the journal. Therefore, starting with Volume 7, all submissions will go through the new system. This is a step forward for us and we really hope you like the change. In line with our improvement efforts we have also opened a profile at Quality Open Access Market (QOAM) and 
we invite you to evaluate us by completing a 2-minute Valuation Score Card. Your comments and suggestions will help us identify our weaknesses and work on them.

This past year has been an important year for us, not only because of the platform change but also because of the publication of a new Special Volume last June, "The How and Why of Archaeology Outreach", edited by Elizabeth Wright and Matt Law, marking a new milestone with 100 authors involved in all the different sections of the journal. Our statistics keep improving, although with the introduction of OJS we will lose one of them, namely the number of registered users, as registration will not be required anymore. However, after data mining our old database, we identified subscribed colleagues from almost 100 countries, giving meaning to our work. We did so in order to show some statistics at the Third International Conference in Heritage Management, organized by the Initiative for Heritage Conservation in Elefsina (Greece), where we presented a paper about our publishing model, our audience, the journal's impact and challenges, as well as our goals for the future. Hopefully, all our efforts will play their part in removing barriers and achieving our main goal; to become more inclusive for all, with engagement of professionals as a community being a particularly important aspect.

Before presenting the current volume, we wanted to stop for a second on a directly related with public archaeology -and sadly severe- issue: conflict. The impact of the eruption of Daesh on archaeological heritage is dramatic. The rampant destruction of archaeological sites, monuments and other cultural manifestations, not to mention looting, is only surpassed by the unfolding humanitarian crisis of refugees fleeing from conflicted areas and the record numbers of deaths that hit us daily in the news. We strongly condemn the barbarian outcomes of war in all fronts and, although it seems we are trapped in a vicious circle of violence and destruction, we hope it will cease as soon as possible, as long as conflict resolution does not involve even more violence. 
Cultural heritage (i.e. that of the 'enemies') has always been a target during armed conflict, causing irreparable losses, and the reality of Syria and Iraq is just one of many examples. World Heritage in particular is being targeted, in confirmation of a sad fact: the so-called Outstanding Universal Value that UNESCO attributes to World Heritage Sites is not shared universally by all communities (at least as we understand it). And, as hard as it may sound, radical groups are heritage communities too. The example of Daesh is not the only one of an ongoing conflict today. Resolving such conflicts is a complex process requiring urgent and concerted efforts that cannot be sustained through Twitter campaigns (as perhaps was the intention of the \#Unite4Heritage campaign).

But the issue goes far beyond large international conflicts and reaches into the small scale, day-to-day practice; small local issues constantly arise, resulting in a destruction of cultural heritage that never reaches the media. We could talk about general trends, such as Globalization and Capitalism and so on, which, little by little, standardize our lives and cultures and commodify the last remains of 'tradition' and 'heritage' that we preserve, but instead we prefer to focus on those other conflicts where archaeology becomes a burden for people. We tend to prioritise archaeological heritage over people, and one of the roles of public archaeology is (or so we think) to put people before archaeological heritage with management plans sensitive to the needs and concerns of local communities; because archaeology can be not just present but also more active and engaging in everyday life, with small actions and practices that help build communities around cultural heritage for a mutual benefit. Resolving such conflicts is possible, having one eye on people and one on heritage. This is why this Volume's cover is an image from one of our articles, showing a cleaning activity in the surroundings of a heritage property. But what do we have in this volume?

Volume 6 opens with our third forum on looting with the theme "Beauty and money: a market that feeds looting". The forum was 
postponed in 2015, and this past year has not turned out as expected either. However, and despite the fact that it includes only one piece, we decided to publish it without delay. To begin with, Jaime Almansa offers a brief, personal and reflexive account of his time as a young collector of stamps and modern coins and moves on to share some reflections on the link between collecting and looting as an introduction to the forum. He concludes by posing some questions about the issues surrounding looting; the questions, both practical and moral, are not easy to answer but need to be addressed with high priority and with a view to resolve the issue under discussion. Our hope is that not only will you find this small forum interesting but also that it will be a prompt for future submissions on any one of the topics listed in its introduction. Christos Tsirogiannis raises a crucial issue for museums and cultural institutions; the issue of repatriation of illicit antiquities. By using a long-delayed repatriation as a case study, the paper explores the underlying reasons why delays in addressing repatriation claims on the part of institutions involved in the acquisition of illicit antiquities persist in practice. The author highlights the fact that, despite existing guidelines, gaps between theory and practice in museum ethics occur more often than not. Thus, the need for ways to bridge these gaps comes through not only as a central idea in this paper but also as a major challenge faced by institutions and heritage policy makers alike.

What follows is a collection of papers that we believe you will find interesting. In our first article, Veysel Apaydin explores an issue that is crucial for the protection or neglect for heritage: by means of qualitative and quantitative analysis of the curriculum and history textbooks in Turkish formal education as well as interview data, the author examines to what extent and how topics related to archaeology and heritage are presented, and discusses the implications for heritage perceptions and awareness.

Next, Jaime Delgado Rubio examines social participation as viewed and practised by the Mexican state and institutions through 
participatory heritage management plans, juxtaposing the latter to the dynamics and processes of other, specific micro-scale cases of community participation. The author suggests a revision of the current top-down approach in participatory heritage management and argues that alternative, more inclusive methodologies and models need to be sought.

Finally, José Mármol examines new ways to 'view' archaeology. In recent years, archaeologists have explored the potential of the so-called Creative Archaeologies that blur the boundaries - not only those between disciplines and practices but also spatial and temporal boundaries. Starting from the premise that archaeological practice should address the problems of the present rather than merely study and interpret the past, and that Creative Archaeologies can contribute to the interpretation of the past, the author uses three different, parallel discourses that lead to a discussion of the opportunities and impact of integrating creative practices into the archaeological.

This volume also features our regular Points of You section, only this time it includes two pieces. Rogers and Case discuss native peoples' perspectives in US archaeology. The authors examine academic and tribal archaeological approaches to artifacts, alongside authority, power and representation issues, through specific examples that illustrate the power dynamics between involved parties. Finally, Rogers and Case stress the need for more collaborative work and more inclusive practices, and propose a set of guidelines for working alongside native peoples. Jošt Hobič offers his own viewpoint on the present of archaeology, its public image and its value not only for local communities but also for-and starting with-professionals in Slovenia and elsewhere. The author acknowledges that there is room for improvement and argues strongly for community archaeology.

As always, this issue concludes with a selection of reviews of some of the most interesting books published in the last couple of years on topics that pertain to public archaeology. Although book reviews 
are usually undervalued, they are a highly valued component of AP Journal and an integral part of dialogue in any discipline. We consider the reviews we publish equally important for authors and readers alike, thus we really hope they prove useful. Finally, we would like to remind you that we regularly publish reviews of events as well as links to Open Access theses in our blog.

This Volume, as every Volume we publish, is the culmination of months of hard work by the editors, editorial team, and contributors, all committed to making public archaeology research openly available and making open access the default for research. At this point, we should thank all those that have made it possible for us to continue up to this day: our authors and guest editors, our editorial team, our readers, and our donors. As usual, we hope you will enjoy our new volume and find it useful. We would like to close this editorial with our standard calls:

\section{Call for Debate:}

We welcome guest blog posts on a wide range of topics related to public archaeology as well as event reviews. You can send your posts in a Word document with image files attached to our email. We also encourage your feedback and comments, after visiting our blog, as well as discussion via our social media. If you have any specific topic in mind that you want to write about, we are open to suggestions. Don't forget our forums that are always open to discussion and comments.

\section{Call for Papers:}

Volume 7 is set to be published in 2017. Because of the delay in publication of the current volume, the deadline for submissions is extended by one month, and will be 31 May 2017. We wish to receive papers for our next volume as soon as possible so that there will be enough time to get things done in a timely, consistent manner. For more information about the submission 
procedure, please visit our website. In case you have any questions or doubts, please feel free to contact us.

3. Call for Special Issue Proposals:

We invite guest editor proposals from those who wish to discuss particular topics and areas of research that fall within the aims and scopes of the journal. Special issues provide a great opportunity to review a specific topic, examine aspects that remain unaddressed, discuss, suggest and develop novel approaches, and encourage new research models. Feel free to contact us for guidance on preparing your proposal.

4. Call for Donations:

The philosophy of this journal-and of its editors-is to provide the widest access at no cost for both authors and readers. AP isand will remain-a free-access and not-for-profit journal, thus, sustainability is always an issue. The publisher, JAS Arqueología, will continue to take care of it for as long as it exists. The material costs of the journal are less than $100 €$ per year, which is affordable for the company in case donations are low, but keeping it a fully open-access and ad-free publication means its future depends on your support. So if you find any stimulation in AP Journal, please consider a modest donation. No matter how small the amount, it can make a big difference.

At this point, we should warmly thank and express our gratitude to our donors. Should you wish to support AP Journal, you can do so either directly or indirectly, by buying a hard copy of any of the existing volumes:

- Direct donation via PayPal on our web page.

- Purchase of the hard copy. There is a fixed price of $10 €$. Just ask us. 
